\title{
AN INVESTIGATION OF MACHINABILITY OF INCONEL 718 IN EDM USING DIFFERENT CRYOGENIC TREATED TOOLS: A REVIEW
}

\begin{tabular}{|l|l|l|}
\hline Pradeep Joshi & Jaspreet Singh & Shiv Dayal Dhakad \\
Department of Mechanical Engineering & Department of Mechanical Engineering & Department of Mechanical Engineering \\
Lovely Professional University & Lovely Professional University & Lovely Professional University \\
Phagwara, Punjab, India & Phagwara, Punjab, India & Phagwara, Punjab, India \\
Pradeep.joshi93@gmail.com & jaspreet.17676@1pu.co.in & $\underline{\text { shivdhakad999@gmail.com }}$ \\
\hline
\end{tabular}

\begin{abstract}
Inconel 718 is a family of Nickel-Chromium based Superalloy; it has very high oxidation and corrosion resistance. Inconel 718 is widely being used in aerospace, engine, turbine etc. due to its high mechanical strength and creep resistance. Being widely used, its machining should be easy but in real its machining is very difficult, especially by using traditional machining methods. It becomes easy to machine only by using non Traditional machining such as EDM. During EDM machining there is wear of both tool and workpiece, the tool wear is undesired because it changes tool shape, geometry. To reduce the tool wear rate (TWR) cryogenic treatment is performed on tool before the machining operation. The machining performances of the process are to be evaluated in terms of MRR, TWR which are functions of Discharge current, Pulse on-time, Pulse Off-time.
\end{abstract}

Keywords - EDM, cryogenic, MRR, TWR

\section{INTRODUCTION}

Advance materials such as superalloys etc. have become a very important part of engineering application because of their excellent chemical and mechanical properties at high temperatures [1]. The properties such as high wear resistance, high corrosion resistance [2], high creep resistance [3], high hardness makes their use essential in power industries, aerospace industries, rocket motor, nuclear reactors $[4,5]$. But the main problem with these material is their poor machinability [3]. Nickel based superalloy comprise of broad group of superalloy [6]. Nickel based superalloy can be divided into three broad categories: (i) Nickel-chromium e.g. Inconel, waspaloy etc. (ii) Nickel- molybdenum-chromium e.g. Hastelloy etc. (iii) Nickel- copper e.g. Monel etc. [5]. Out of the three category Nickel-Chromium superalloy are broadly used specially Inconel 718 . Conventional machining of Nickel based alloy produces a very high temperature which leads to wear, plastic deformation of tool cutting edge because of low thermal conductivity of the material [3] for this reason non-conventional machining is more preferable for machining superalloys. Talking broadly drilling operation constitute $30 \%$ of total machining followed by turning operation 20\%, milling operation $16 \%$ and threading operation $16 \%$ [6]. As the best method for drilling hard material is EDM. EDM is controlled metal removal process which removes metal by spark erosion. It is an Electro thermal process in which the material removes by the process of melting and vaporization. EDM is widely used to produce moulds and dies [2] and for the finishing of automotive and aerospace parts [3]. For the removal of metal high frequency electrical current is supplied by pulsating charge to the tool; resulting in spark that strike to the workpiece surface and erodes the material in the debris form. The complete process occur at control rate resulting small amount of metal removal. The area of workpiece where spark strikes melts and evaporates by the plasma channel having high density, the resulting temperature is around $8000-10000{ }^{\circ} \mathrm{C}$. The complete process of EDM can be divided into four stages: (i) Apply the electrical energy (ii) Breakdown of dielectric medium (iii) Sparking between workpiece and electrode (IV) Removal of metal from the workpiece and flushing them away from w/p surface. Since the EDM is being an indispensable operation in the manufacturing processes, it has been in the center of interest for researchers. EDM machines are advancing day by day because of their important roles some of the advancement of EDM are known as CNC EDM, Wire EDM, and Dry EDM. But there are also some problems that are associated with EDM while machining hard materials such as high tool wear and low surface finish. Our main aim is to reduce the tool wear for which cryogenic treatment can be performed on the tool. Cryogenics, is the science of study of low temperature and production of at those low temperatures. The cryogenics temperature concerned is not exactly defined but it fall in ranges between temperatures $-150^{\circ} \mathrm{C}$ to $-273.15^{\circ} \mathrm{C}$ which is absolute zero, by the cryogenic heat treatment a very low temperature is attained. In cryogenic treatment process the tools is being immersed into the liquid nitrogen (LN2) for certain period of time. The cryogenic processing are operated in 3 main stages namely cold down, soaking, warm up and tempering because if the tool is directly immersed it will generate thermal shocks in the tool [7].

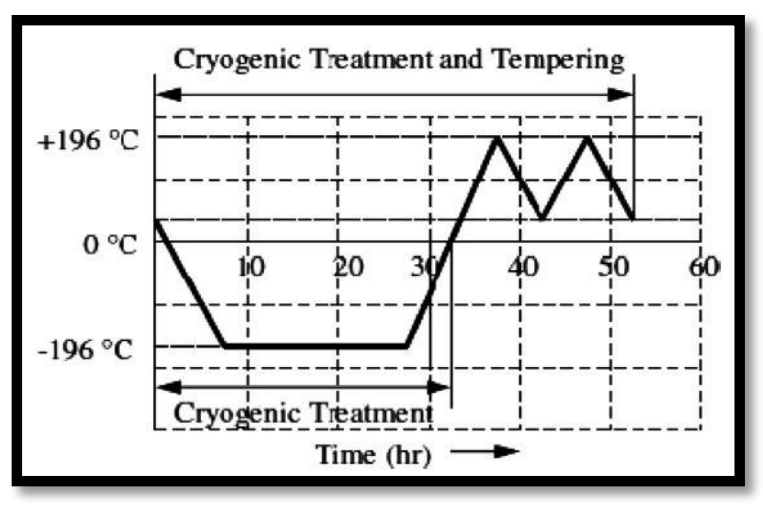

Figure 1 Time- Temperature graph for Cryogenic Treatment

During any manufacturing operation material is subjected to stresses and in the crystal structure of materials the stress reveal itself in the nature of defects. Dislocations, vacancies and stacking faults etc. are the most common observed defects. Increasing the level of stress, increases the density of the defects, leading to increase in inter atomic spacing which leads to failure. Cryogenic treatment relieves the stress when subjected for a period of time as the cryogenic treatment eliminates austenite via isothermal martensite phase transformation at low temperature. Furthermore during the 


\section{Asia Pacific Journals}

cryogenic treatment austenite and martensite endures high amount of contraction due to low temperature. The high degree of stress decompose martensite. The defect generated acts as a preferential site for wandering carbon atom. These carbon then produce eta carbide $(\eta)$ and increases total carbide percentage and produces homogenous distribution. The retained austenite reduction, higher carbide percentage increase adhesive and erosive wear, hardness, fatigue strength and corrosion resistance $[6,7]$.

\section{LITERATURE REVIEW}

\section{(i) EDM Literature review}

Pellicer et al. [2011] studied the effect of different process parameters like pulse on time, pulse off time, discharge current and open voltage by using copper electrodes of different geometries on AISI H13 using ANOVA designed experiment on EDM. The output parameters studied were material removal rate, different geometrical and the dimensional micro accuracies and the surface roughness. It was found that by increasing the discharge current the material removal rate increases. Square and rectangle electrodes were better for both the wear ratios i.e. radial wear ratio and the axial wear ratio.

Singh[2012] worked on Die sinking EDM machine to study the effect of copper chromium and aluminum electrode on EN31. In this Authors evaluate process performance criteria such as material removal rate, electrode wear rate, hardness, depth of cut and over cut. Authors found that brass electrode has a more depth of cut and hardness but copper chromium has a more material removal rate with lower electrode wear.

Yoo et al. [2013] experimented on EDM and compared machining capability of commercial WC (tungsten carbide) electrode with that of the home made cermets electrode which was prepared by milling and sintering of $\mathrm{Ti}(\mathrm{C}, \mathrm{N})$ and $(\mathrm{Ti}, \mathrm{W})(\mathrm{C}, \mathrm{N})$ along with various carbides, nitrides to drill a micro-hole in a stainless steel thin plate (SS304). During a micro-hole machining process with a Ti-based solid solution carbon nitride electrode, under optimal conditions for the Ti based electrode the EWR was improved by $35.38 \%$ and machining time by $45.16 \%$ as compared to the EWR for a WC-Co electrode, while for WC-Co electrode, the EWR was improved by $17.0 \%$ and the machining time by $18.8 \%$ as compared to the EWR for a WC-Co electrode. So the performance of Ti-based solid solution carbon nitride was found better than that of WCCo for a micro-hole machining EDM process.

Das et al. [2013] investigated about the optimum combination of process parameter in EDM process so that surface roughness reaches a minimum value and the metal removing rate reaches a maximum value on EN31. Authors considered five roughness parameter root mean square roughness, Center line average roughness, skewness and kurtosis along with MRR and mean line
ISBN: 978-81-930411-4-7

peak spacing. To optimize the multi response problems only Taguchi method alone is unable to solve the problem. That is why the multi response characteristics must be converted to a single performance index so Principal components analysis (WPCA) method is used for conversion. The result of machining showed that discharge current is the most influencing parameter that significantly affects the roughness and MRR characteristics at a confidence level of $95 \%$.

Raghuraman et al. [2013] optimized the EDM parameters for the important need of the industries for the quality products at the lower costs to get the better manufacturing conditions and the beneficial techniques. Mild steel IS2026 was taken as workpiece and the copper as a electrode tool with the three output parameters such as electrode wear ratio, material removal rate and the surface roughness finish with the number of input parameters such as discharge current, pulse-on and pulse-off time. By using Grey Relational Analysis which is a Taguchi method analysis were done and the experiments were conducted by using the L9 orthogonal array. By the experiment authors found that there are certain parameter combination which showed the better result such as pulse current at $26 \mathrm{~A}$, pulse ON time at $55 \mu \mathrm{s}$ and pulse OFF time at $5 \mu \mathrm{s}$.

Nikalje et al. [2013] worked on Influence of parameters and optimization of EDM performance measures on MDN 300 steel using Taguchi method. In this Authors evaluated process performance criteria such as material removal rate (MRR), tool wear rate (TWR), relative wear ratio (RWR), and surface roughness (SR) and Selected Parameters which affects EDM performance were Discharge current, pulse on time, and pulse off time. Authors have found that the optimal level of the factors for SR and TWR are same but differs from the optimum levels of the factors for MRR and RWR. Authors found that discharge current, pulse on time, and pulse off time have been found to play significant role in EDM operations. From the result they have found that study of Surface morphological indicates that at higher discharge current and longer pulse on duration gives rougher surface characteristics with more craters, globules of debris, and micro cracks than that of lower discharge current and lower pulse on duration

Sharma et al. [2014] worked on Die sinking EDM machine to study parameters on AISI- 329 using copper and brass rotary electrode during EDM process. In this Author evaluate process performance criteria such as material removal rate and electrode wear rate and taper angle of the hole in AISI 329. Confirmation of the experimental data is done by ANOVA. Authors found that copper electrode improve hole quality and provide good machinability as comparison to brass electrode.

Khan et al. [2014] worked on Die sinking EDM machine to study the surface finish of Ti-5AL-2.5Sn during EDM 
process to evaluate surface roughness. Authors found that material of electrode affects surface roughness. Authors also found that at low discharge energy, copper-tungsten electrode gives an excellent surface structure as compared to graphite electrode.

\section{(ii) Cryogenic treatment review}

\begin{abstract}
Ahmed et al. [2008] modified a tool to apply liquid nitrogen as coolant through a hole made in the tool so that liquid nitrogen can be directly applied to the machining zone during machining of stainless steel with carbide tools coated with titanium carbonitride. It was found that the tool life increased by more than four times on the application of liquid nitrogen using the modified tool.
\end{abstract}

Khan et al. [2009] studied the cooling effect of copper electrode on the die-sinking EDM of titanium alloy (Ti$6 \mathrm{Al}-4 \mathrm{~V})$ and studied their effect on surface roughness and electrode wear. After the experiment they found that liquid nitrogen reduces the temperature of copper electrode thereby minimizes its vaporization and melting, and also the cooling effect of liquid nitrogen improves the thermal and electrical conductivities of copper. This results in efficient heat transfer away from the copper electrode reducing its wear.

Gill and Singh [2010] investigated on the machining of the Ti6264 alloy in the EDM and studied about deep cryogenic heat treatment effect on the alloy by drilling it with conducted electrolytic copper tool. And also studied about the accuracy of the drilling holes in the alloy and compared the surface roughness finish and the overcut of Ti6246 which is cryogenically cooled with one which is not cryogenically cooled. On both the workpiece total six drilling setups experiments are performed one setup of drilling for both the workpiece are $30 \mathrm{~min}, 60 \mathrm{~min}, 90 \mathrm{~min}$, $120 \mathrm{~min}, 150 \mathrm{~min}$, and $180 \mathrm{~min}$. From experimentation it is found that the deeply cryogenically cooled Ti 6246 alloy improves the machining condition in the electric discharge machining. The improvement that has shown for different drilling times are up to $8.5 \%$ for MRR, $34.78 \%$ for TWR, and $30.16 \%$ for wear ratio.

Amini et al. [2012] investigated on the tool steel 1.2080 having diameter of $50 \mathrm{~mm}$ about the time duration of the liquid nitrogen applied for the deep cryogenic heat treatment process and studied about the changes occurred in the micro structure, in the distribution of the carbide and in the carbide percentage, hardness and the micro hardness. Authors performed these analyses via the scanning electron microscope, transmission electron microscope, $\mathrm{X}$ ay diffraction and optical microscope. By the deep cryogenic heat treatment there is increase in the percentage of the carbide and the austenite is removed. Due to improvements in the deep cryogenically cooled samples the hardness and the micro hardness is increased. In application durations more than 36 hours, the hardness and the micro hardness is decreased due to the decrease in the carbide percentage in the sample as compared to the uncooled samples In other words we can say that at the 36 hours for the application of liquid nitrogen the hardness, micro hardness and microstructure uniformity and carbide percentage attained its optimum value

Srivastava and Pandey [2012] performed a set of experiments on the EDM to study the effect of cooling on copper electrode and M2 grade high speed steel workpiece. Discharge current, duty cycle, gap voltage and pulse on time were the controllable input process parameters on which authors worked. From experimentation, authors have found that with the increase of duty cycle and the discharge current electrode wear rate increases for both EDM and cryogenic EDM processes. The EWR decreases with increase in pulse on time, however, for the same pulse-on time; EWR is higher as discharge current increases. It is observed that the SR increases with the increase in the discharge current up to $6 \mathrm{~A}$, and then it slightly decreases for both the processes. An increase in pulse-on time with increase in discharge current increases the SR in both the processes. The experimental findings for same parameters are that electrode wear ratio and surface roughness as compared to conventional EDM is lower in cryogenically treated EDM. The reduction of tool wear occurred due to the use of liquid nitrogen.

Singh and singh, [2013] worked on EDM by using cryogenic electrode to increase the MMR and lowering of the TWR by using cryogenic and non-cryogenic electrode with pulse on/off and current as parameter. With the increscent in the pulse on time tool wear rate of copper is decreased in both electrode cryogenic treated copper electrode and non-cryogenic copper electrode. And tool wear rate is increased with increase in pulse off time. Tool wear rate is very less in cryogenic treated copper electrode as compared to non-cryogenic treated electrode.

Srivastava and Pandey [2013] had been studied on the electrical discharge machining which is ultrasonic assisted cryogenically cooled on the copper titanium carbide electrode tip which is sintered. The process parameter considered were discharge current, gap voltage, duty cycle, and pulse-on time. Cermet was fabricated having copper content of $75 \%$ and titanium carbide content of $25 \%$, by mixing, pressing, and sintering. Analysis has been done to study about the comparison of the convectional cooper electrode for electrical discharge machining which is ultrasonic assisted cryogenically cooled with performance cermet electrode tip which is newly formed From analysis it had been found that duty cycle, pulse on and discharge current time have most significant effect on the electrode wear ratio in UACEDM process and that electrode wear rate increased with increase in discharge current, and for same set of parameters, electrode wear rate was lowered when cermet tool tip was used as compared to $\mathrm{Cu}$ tool tip. It had also been analyzed that MRR and SR increase when cermet tooltip was used as compared to $\mathrm{Cu}$ tooltip. By examining the machined surface, it was observed that the amount of recast layer formation and surface cracks decreased when machined by cermet tooltip as compared to $\mathrm{Cu}$ tooltip. 
Liqing and Yingjie [2013] performed a set of experiments on the EDM with oxygen, nitrogen, argon and compressed air with quenched 45 carbon steel as work material and copper tube the tool. Amongst all these gases, it has observed that maximum MRR is with the oxygen gas. MRR of oxygen mixed dry EDM was increased greatly as compared to the non-oxygen, single gas dry EDM, by no less than $200 \%$. Then further a cryogenic cooling device was set to cool the work piece effectively by using liquid nitrogen coolant contained in a kettle shaped vessel. A copper tube electrode of outer diameter $6.0 \mathrm{~mm}$ and inner diameter of $3.0 \mathrm{~mm}$ was used with different parameters like pulse off and pulse on time, gap voltage, peak current and compressed air pressure. By increasing the peak current value, the MRR was found to increase as compared to the results for obtained for work piece without cooling. Cryogenically cooled machining marginally improves the $\mathrm{SR}$ value. The MRR and $\mathrm{SR}$ can be improved for cryogenically cooled workpiece with both positive and negative polarities.

Mohandoss R. performed cryogenic treatment of EN - 19 alloy steel material to improve its mechanical behavior. The material was deep cryogenic treated at $-191^{\circ} \mathrm{C}$ for 24hrs. The mechanical behavior of untreated EN-19, case carburized EN-19 and carburized and cryogenic treated EN - 19 were found by conducting tests such as tensile testing, impact strength and Rockwell hardness. The tensile strength in cryogenic treatment is increased by $22.62 \%$ and in carburized it is increased by $7.94 \%$ as compared to un-treated material. The hardness in cryogenic treated steel is increased by a amount of $55 \%$. The result also shows that ductile material is converted to brittle material by the application of cryogenic treatment.

(iii) Reviews of Inconel 718 machining

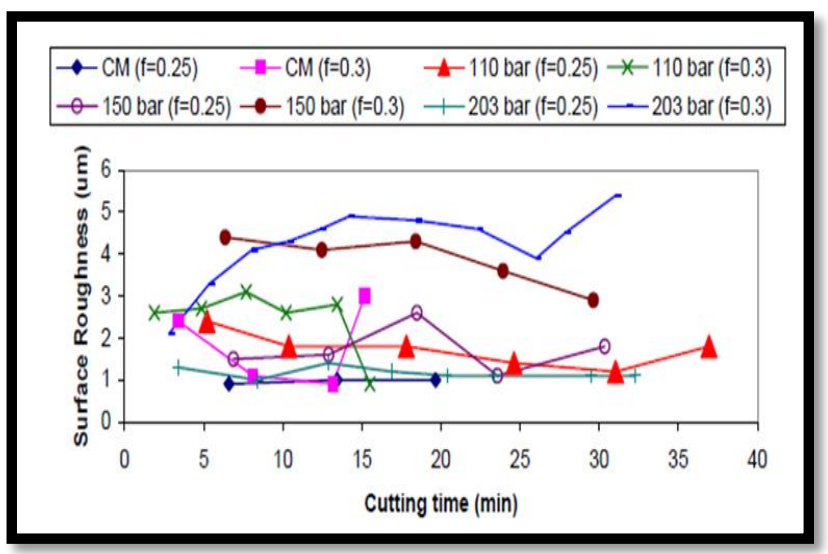

Figure 3 Surface roughness v/s cutting speed ( Ezugwu et al.)

Ezugwu et al. [2004] studied the effect of varying coolant pressure on tool performance during machining of Inconel 718 with coated carbide tools at high cutting speed. The cutting speed were $20,30,50 \mathrm{~m} / \mathrm{min}$ along with a feed rate of 0.25 and $0.3 \mathrm{~mm} / \mathrm{rev}$ and a depth of cut of 2.5-3.0 mm, the coolant supply pressure were 110, 150, 203 bar. The parameter observed were tool life, surface roughness and tool wear. The result obtained shows that machining under high coolant pressure increases the tool life by 7 folds, machining at 203 bar coolant pressure produces well segmented chips, at a cutting speed of 20 $\mathrm{m} / \mathrm{min}$ it was also found that there were an increase in nose wear rate using 203 bar as coolant pressure at both the feed rates. Low value of surface roughness were observed at low feed rate and an increase in feed rate leads to increase in the surface roughness.

Nalbant et al. [2006] studied the effect on cutting force by varying cutting speed and cutting tool geometry. Inconel 718 is machined with 4 different ceramic tools (KYON 2100 SNGN 120712, KYON 4300 SNGN 120712, KYON 2000 RNGN 120712 and KYON 4300 RNGN 120700) at various cutting speeds which are $150 \mathrm{~m} / \mathrm{min}, 200 \mathrm{~m} / \mathrm{min}$, $250 \mathrm{~m} / \mathrm{min}, 300 \mathrm{~m} / \mathrm{min}$ along with depth of $2 \mathrm{~mm}$ and feed rate of $0.20 \mathrm{rev} / \mathrm{min}$ which was kept constant throughout the experimentation. The lowest cutting force was $672 \mathrm{~N}$ and the highest was $1346 \mathrm{~N}$. An increment-decrement relationship is found between cutting speed and cutting force. Increasing the cutting speed by $66.6 \%$ (150$250 \mathrm{~m} / \mathrm{min}$ ) decreases the cutting force by $14.6 \%$ and increasing the cutting speed by $20 \%$ increases the cutting force by $10.4 \%$ because high cutting speed of Inconel leads to plastic deformation, crater, notch wear and side surface of tool, the lowest value of cutting force is found at $250 \mathrm{~m} / \mathrm{min}$. It was also found that increasing tool tip radius increases main cutting force. The cutting force of tool KYON 4300 RNGN 120700 was higher as compared to other three tool produced similar force.

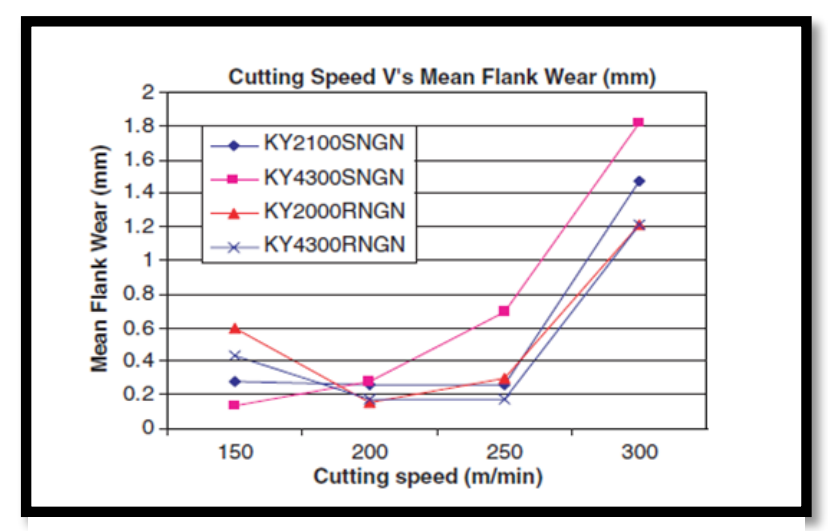

Figure 2 Cutting speed v/s Mean Flank Wear

Altin et al.[2006] studied effect of cutting speed on tool life and tool wear during the machining of NBSA Inconel 718. The tools used during the experimentation is whisker reinforced aluminum oxide ceramic tool $\mathrm{Al} 2 \mathrm{O} 3+\mathrm{SiCw}$ (KYON 4300 SNGN 120712 and KYON 4300 RNGN 120700) and silicon nitride (KYON 2000 RNGN 120700 and 2100 SNGN 720112) based tool having two different geometry (square shape and round shape) and three different ISO qualities with $10 \%$ water additive cutting fluid. The cutting speed was taken between $150 \mathrm{~m} / \mathrm{min}$ to $300 \mathrm{~m} / \mathrm{min}$ and a constant feed and depth of cut is maintained viz. $0.20 \mathrm{~mm} / \mathrm{rev}$ and $2 \mathrm{~mm}$. The wear in round type inserts are notch and flank while in square one crater and flank wear are major. The optimum cutting speed deducted from experiment is $250 \mathrm{~m} / \mathrm{min}$. At low cutting speed the performance of square was good them round 
type inserts and at high cutting speed round was better than square type inserts.

Kuppan et al. [2008] studied the effect of deep hole drilling of Inconel 718 by copper tool (dia $3 \mathrm{~mm}$ ) using EDM. The parameter investigated were electrode speed, pulse on-time, duty-cycle, and peak current and CCD is used for planning of experiment. The results obtained shows that increasing the current increase the MRR. The MRR increases with increase in peak current, electrode rotation and duty-cycle while pulse on-time increases MRR up to $60 \mu \mathrm{s}$ beyond this MRR decreases and also increasing the electrode speed increases the MRR. Results also shows that increase in current and pulse on-time increases average surface roughness while it decreases with increasing duty cycle and electrode rotational speed.

Thakur et al. [2009] studied the machinability of Inconel 718 using tungsten carbide (K20) tool and the parameter investigated are cutting temperature, cutting pressure, cutting force, surface finish and tool wear. The cutting speed was in between $40-60 \mathrm{~m} / \mathrm{min}$, feed $0.05-0.09$ $\mathrm{mm} / \mathrm{rev}$ and the depth of cut $0.5 \mathrm{~mm}$. The result shows that cutting force was in good condition in a speed range of 45$55 \mathrm{~m} / \mathrm{min}$ but after $60 \mathrm{~m} / \mathrm{min}$ there is an increase in tool wear rate, it was also found that there was a reduction in specific cutting pressure as the cutting speed increases at constant depth and feed rate. Increasing the feed and speed increases the temperature at tool-chip interface. The feed rate of $0.08 \mathrm{~mm} / \mathrm{rev}$ and a cutting speed in between $45-55$ $\mathrm{m} / \mathrm{min}$ gives optimum surface roughness. The plastic deformation was found in high amount.

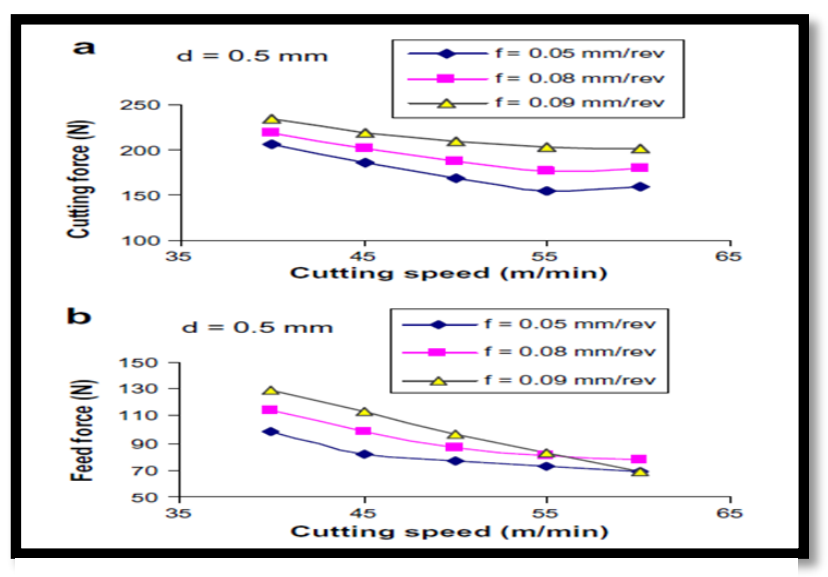

Figure 4 Cutting Force v/s Cutting speed

Baghlania et al.[2013] investigated the effect of spindle speed(355rpm,500rpm,710rpm), number of drilling steps $(1 * 50 \mathrm{~mm}, \quad 3 * 17 \mathrm{~mm}, \quad 5 * 10 \mathrm{~mm})$, ultrasonic vibration amplitude $(3 \mu \mathrm{m}, 6 \mu \mathrm{m}, 10 \mu \mathrm{m})$ on surface roughness and machining force during ultrasonic assisted drilling of Inconel 738LC using Taguchi methods keeping a constant feed of $0.05 \mathrm{~mm} / \mathrm{rev}$. The results shows that increasing vibration amplitude decreases the thrust force and gives better surface roughness, increasing spindle speed increases force and reduce surface roughness.

Motorcu et al. [2014] studied the effects of cutting speed ( $17 \mathrm{~m} / \mathrm{min} 20 \mathrm{~m} / \mathrm{min}, 24 \mathrm{~m} / \mathrm{min})$, feed $(27 \mathrm{~mm} / \mathrm{rev}$,
$32 \mathrm{~mm} / \mathrm{rev}, 39 \mathrm{~mm} / \mathrm{rev})$, drill bit angle( $980,1180,1420)$ and cutting tool type were investigated during the drilling of Waspaloy with coated and uncoated solid carbide drills using Taguchi method. The overall mean value of surface roughness was $0.99 \mu \mathrm{m}$, coated drill bit provide lower surface roughness compared to uncoated, also. Surface roughness increasing with increase cutting speed, drill bit angle and with increasing tool wear. Drill bit angle was found to be the most effective parameter on surface roughness followed by feed rate viz. $15 \%$, cutting speed viz. $14.45 \%$ and cutting tool viz. $13.51 \%$. There was no wear found in uncoated tool while chipping and flank wear was found in coated tools.

Laxman et al. [2014] studied the effect of various parameters such as peak current, pulse on-time, pulse offtime and tool lift time during machining of Inconel 718 with copper electrode using EDM to measure MRR and TWR by Grey relational analysis. It was found that by the proper optimization both the TWR and MRR were improved. The MRR increases from $3.9 \mathrm{mg} / \mathrm{min}$ to 7.7 $\mathrm{mg} / \mathrm{min}$ and TWR decreases from $0.3 \mathrm{mg} / \mathrm{min}$ to 0.2 $\mathrm{mg} / \mathrm{min}$.

Mahapatra et al. [2014] studied the effect of various parameter during the machining of Inconel 718 by different tools i.e. Graphite, Copper and Brass using EDM to measure MRR and SR. The parameter studied were discharge current, flushing pressure, pulse on-time, duty factor, open circuit voltage and tool material, for the optimization of the result a Box-Behnkin design of response surface methodology is used. The result found that in case of copper and graphite tool, MRR increases monotonically with current but increases slowly with brass tool. The highest MRR is given by graphite tool followed by copper and brass, MRR increase with increase in voltage till a certain point and then decreases. Brass shows good surface finish while Copper and graphite exhibit poor surface finish also increasing the pulse on time decrease the surface quality.

\section{Acknowledgment}

The author would like to thanks all the professor and my fellow researchers for their valuable guidance and constant help during the work.

\section{References}

[1] Lia L., Guo Y.B., Wei X.T., Li W., Surface integrity characteristics in wire-EDM of inconel 718 at different discharge, Procedia CIRP 6 (2013) 220 - 225

[2] Baghlania V., Mehbudia P., Akbarib J. , Sohrabic M. , Ultrasonic assisted deep drilling of Inconel 738LC superalloy, Procedia CIRP 6 ( 2013 ) 571 - 576

[3] Ezugwu E.O. ,Bonney J., Effect of high-pressure coolant supply when machining nickel-base, Inconel 718, alloy with coated carbide tools, Journal of Materials Processing Technology 153-154 (2004) 1045-1050 
[4] Kuppan P. \& Rajadurai A. \& Narayanan S., Influence of EDM process parameters in deep hole drilling of Inconel 718, Int J Adv Manuf Technol (2008) 38:74-84

[5] Motorcu Ali Riza , Kus Abdil, Durgun Ismail, The evaluation of the effects of control factors on surface roughness in the drilling of Waspaloy superalloy, Measurement 58 (2014) 394-408

[6] Kamran Amini , Amin Akhbarizadeh, Sirus Javadpour, Investigating the effect of holding duration on the microstructure of 1.2080 tool steel during the deep cryogenic heat treatment, Vacuum 86 (2012) 1534-1540

[7] Patil P I, Tated R G , Comparison of Effects of Cryogenic Treatment on Different Types of Steels: A Review, International Conference in Computational Intelligence (ICCIA) 2012

[8] Pellicer, N., Ciurana, J. and Delgado, J. (2011) Tool electrode geometry and process parameters influence on different feature geometry and surface quality in electrical discharge machining of AISI H13 steel, 22: 575-584

[9] Singh Harpuneet, Investigating the Effect of Copper Chromium and Aluminum Electrodes on EN-31 Die Steel on Electric Discharge Machine Using Positive Polarity, World congress on Engineering, Vol. 3, 2012

[11] Yoo, H.K., Kwon, W.T. and Kang, S. (2013) Development of a New Electrode for Micro-Electrical Discharge Machining (EDM) using Ti(C,N)-based Cermet , International Journal of Precision Engineering and Manufacturing, 15( 4): 609-616

[12] Das, M.K., Kumar, K., Barman, T.K. and Sahoo, P. (2013) Optimization of Surface Roughness and MRR in EDM using WPCA, International Conference of Design and Manufacturing, 446-455

[13] Raghuraman, S., Thiruppathi, K., Panneerselvam, T. and Santosh, S. (2013), Optimization of EDM parameters using tauchi method and grey relational analysis for mild steel IS 2026, International Journal of Innovative Research in Science, Engineering and Technology, Vol. 2

[14] A. M. Nikalje \& A. Kumar \& K. V. Sai Srinadh, Influence of parameters and optimization of EDM performance measures on MDN 300 steel using Taguchi Method, Int J Adv Manuf Technol(2013), 69:41-49

[15] Priyaranjan Sharma , Sujit Singh and Dhananjay R Mishra, Electrical discharge machining of AISI 329 SS using copper and brass rotary tubular electrode, Procedia materials science 5(2014)1771-1780

[16] Md. Ashikar Rahman Khan. M.M.Rahman. K.Kadirgara,An experimental investigation on surface finish in die-sinking EDM of Ti-5AL-2.5Sn, Int J Adv Manuf Technol(2014)

[17] Khan, A.A.; Ahmed, M.I. Improving tool life using cryogenic cooling. Journal of Materials Processing Technology, 2008, 149-154

[18] Suleiman Abdulkareem \& Ahsan Ali Khan \& Mohamed Konneh, Reducing electrode wear ratio using cryogenic cooling during electrical discharge machining, Int J Adv Manuf Technol (2009) 45:1146-1151

[19] Gill Simranpreet Singh \& Singh Jagdev (2010) Effect of Deep Cryogenic Treatment on Machinability of Titanium Alloy (Ti-6246) in Electric Discharge Drilling, Materials and Manufacturing Processes, 25:6, 378-385, DOI: $10.1080 / 10426910903179914$

[20] Kamran Amini , Amin Akhbarizadeh , Sirus Javadpour, Investigating the effect of holding duration on the microstructure of 1.2080 tool steel during the deep cryogenic heat treatment, Vacuum 86 (2012) 1534-1540

[21] Vineet Srivastava and Pulak M. Pandey, Performance Evaluation of Electrical Discharge Machining (EDM) Process Using Cryogenically Cooled Electrode, 2012, P 683-688

[22] Singh, H. and Singh, A.,(2013), Effect of Pulse on / Pulse off on Machining of Steel Using Cryogenic Treated Copper Electrode, International Journal of Engineering Research and Development, Volume 5, PP. 29-34

[23] Srivastava, V. and Pandey, P.M. (2013) Study of ultrasonic assisted cryogenically cooled EDM process using sintered $(\mathrm{Cu}-\mathrm{TiC})$ tooltip, Journal of Manufacturing Processes 15: 158-166

[24] Liqing, L. and Yingjie, S. (2013) Study of dry EDM with oxygen-mixed and cryogenic cooling approaches, Procedia CIRP 6: $344-350$

[25] Mohandoss R., Mechanical behaviour of cryogenically treated EN - 19 alloy steel, International journal of power control signal and computation (IJPCSC) Vol. 1 No. 4 ISSN: 0976-268X

[26] Ezugwu E.O., Bonney J., Effect of high-pressure coolant supply when machining nickel-base Inconel 718 alloy with coated carbide tools, Journal of Materials Processing Technology 153-154 (2004) 1045-1050

[27] Nalbant Muammer, Altın Abdullah, Gokkaya Hasan, The effect of cutting speed and cutting tool geometry on machinability properties of nickel-base Inconel 718 super alloys, Materials and Design 28 (2007) 1334-1338

[28] Altin A., Nalbant M., Taskesen A., The effects of cutting speed on tool wear and tool life when machining 


\section{Asia Pacific Journals}

Inconel 718 with ceramic tools, Materials and Design 28 (2007) 2518-2522

[29] Kuppan P., Rajadurai A. \& Narayanan S., Influence of EDM process parameters in deep hole drilling of Inconel 718, Int J Adv Manuf Technol (2008) 38:74-84

[30] Thakur D.G., Ramamoorthy B., Vijayaraghavan L., Study on the machinability characteristics of superalloy Inconel 718 during high speed turning, Materials and Design 30 (2009) 1718-1725

[31] Baghlania V., Mehbudia P., Akbarib J., Sohrabic M., Ultrasonic assisted deep drilling of Inconel 738LC superalloy, ISEM, Procedia CIRP 6 ( 2013 ) 571 - 576

[32] Laxman, J. Dr. Raj Guru K., Optimization of EDM Process Parameters on Titanium Super Alloys Based on the Grey Relational Analysis, International Journal of Engineering Research vol. 3, Issue no. 5, pp : 344-348 (2014)

[33] Mohanty Chinmaya P, Mahapatra Siba Shankar, Singh Manas Ranjan, An Experimental Investigation of Machinability of Inconel 718 in Electrical Discharge Machining, ICMPC, Procedia Materials Science 6 (2014) $605-611$ 